Domenico De Giovanni

Lapse Rate Modeling: A Rational Expectation Approach

Finance

Research Group 


\title{
Lapse Rate Modeling: A Rational Expectation
}

\section{Approach}

\author{
Domenico De Giovanni *
}

Finance Research Group - Department of Business Studies

Aarhus School of Business

University of Aarhus

Fuglesangs Allé 4

DK-8210 Aarhus V

DENMARK

Tel.: +4589486425

email: dogi@asb.dk

First version: October, 2007

${ }^{*}$ Large parts of this research was conducted while I was affiliated with the University of Palermo - Italy. I am grateful for suggestions, useful comments and encouragement from Peter Løchte Jørgensen, Andrea Consiglio and Massimo Costabile. Usual caveats apply. 


\title{
Lapse Rate Modeling: A Rational Expectation Approach
}

\begin{abstract}
The surrender option embedded in many life insurance products is a clause that allows policyholders to terminate the contract early. Pricing techniques based on the American Contingent Claim (ACC) theory are often used, though the actual policyholders' behavior is far from optimal. Inspired by many prepayment models for mortgage backed securities, this paper builds a Rational Expectation (RE) model describing the policyholders' behavior in lapsing the contract. A market model with stochastic interest rates is considered, and the pricing is carried out through numerical approximation of the corresponding two-space-dimensional parabolic partial differential equation. Extensive numerical experiments show the differences in terms of pricing and interest rate elasticity between the ACC and RE approaches as well as the sensitivity of the contract price with respect to changes in the policyholders' behavior.
\end{abstract}

JEL Classification Codes: G21, G22.

Keywords: Surrender Option, Prepayment Models, Alternating Direction Implicit methods. 


\section{Motivations}

The surrender option embedded in most of the currently marketed life insurance products is a contractual clause that gives the policyholders the possibility to receive some benefits - the so-called cash surrender valuealso in case of voluntary early termination of the contract. The introduction of this option adds an important source of uncertainty in the timing and in the magnitude of the cash flows that the insurance company must pay in favor of its insured, which may cause serious liquidity problems. Due to some economical reasons, indeed, the lapse rate in a given period may be so high that insurance companies may need to "sell off" assets. Thus, understanding the dynamics that makes policyholders abandon is crucial in the valuation and the management of life insurance liabilities.

As insurance companies try to discourage the use of the surrender option through the introduction of some form of exit fee, competition and regulators impose rules to protect the claims of policyholders. For instance, the Norwegian regulator has recently introduced the right for policyholders to transfer the market value of their insurance or pension contract to another company at the cost of paying only administrative expenses.

This paper deals with the valuation of the liabilities arising from insurance contracts with surrender feature. We aim at modeling the behavior of a cohort of policyholders that face the problem of optimally lapse the same insurance contract subject to frictions, such as taxes and difficulties in recognizing the optimal time of surrender.

The existing literature recognizes the surrender feature as an American 
Contingent Claim (ACC). Apart from Albizzati and Geman (1994), whose paper deals with interest rate linked contracts in a path-dependent options framework, the valuation of such contracts is made through the use of the ACC theory in markets with a constant risk-free rate. In this case the resulting lapse function is concentrated on the unique instant of time corresponding to the optimal stopping provided by ACC theory. Example of this piece of literature are Grosen and Jørgensen (1997, 2000), Steffensen (2002) and Bacinello (2003, 2005), to mention but a few.

Although the surrender feature has all the characteristics of an American Option in the sense that it gives the policyholders the possibility to exercise the contract optimally, in this paper we claim that the policyholders' behavior in lapsing the contract is very far from being optimal. Kuo et al. (2003) provides strong evidence supporting the statement above. The cointegration analysis carried out in that paper clearly shows the existence of a relationship between the lapse rate and the short-term interest rate, as well as the relationships between the lapse rate and the unemployment rate. Further evidence is highlighted in Kim (2005).

With the consideration above in mind, and inspired by Stanton's Rational Expectation Model for mortgage backed securities (Stanton, 1995), this paper presents a rational lapse model based on contingent claims pricing theory. As in the framework of Stanton, we model the surrender behavior by an internal decision process, where policyholders rationally choose whether to exercise the option or not. We also allow for irrational surrenders and transaction costs faced by policyholders, and explicitly model heterogeneity within the pool of insured. Differently from Stanton's, we consider a financial market 
with a stochastic risky asset to model the reference fund of the contract and stochastic dynamics for the short-term interest rate, and model the lapse probability as a fixed, increasing function of the short rate.

The main contribution of this paper to the literature on modeling, valuation and management of insurance products with surrender feature consists in the introduction of a set of rational policyholders behavior in which the surrender option can be evaluated in a market model with stochastic interest rate. The papers mentioned so far are generalized in a double way. First, the model presented in this paper allows for a more general surrender strategy which includes the American Contingent Claim (ACC) approach; and second, we work on a market model with stochastic interest rate (to the best of our knowledge this is a lack in the current literature due the great computational efforts required to evaluate American-type contracts in two-dimensional markets). On the other hand, we also provide an efficient computational tool where index-linked products can be evaluated.

The paper is organized as follows. Section 2 introduces the insurance contracts which will be evaluated as well as the basic modeling framework. Section 3 first describes the decision process of a pool of equally behaved policyholders and then gives indications to adapt it to heterogenous groups. In Section 4 we discuss the basic methodology used to price the surrender option. Section 5 presents selected numerical results, while Section 6 concludes. 


\section{The model}

\subsection{The insurance framework}

At time $t=0$ policyholders enter into a contract with nominal value $G_{0}$ and maturity $T$. The premium that each policyholder must pay to enter into the contract is denoted by $\Pi_{0}$. Here we assume single premium contracts. The insurance company will immediately invest the nominal value of the contract in a well-defined reference portfolio, whose evolution through time is described by the stochastic process $V(t)$. Any dividends of the portfolio is immediately reinvested.

We denote by $B(t) \equiv B(t, V(t))$ the benefit offered by the contract at time $t \in[0, T] . B(t)$ is a function of the reference portfolio, the minimum guarantee rate, $r^{G}$, and the participation coefficient, $\delta$, which entitles policyholders to share the potential firm's gain over the guarantee:

$$
B(t)=G_{t}+\delta \max \left(V(t)-G_{t}, 0\right) \quad t \in[0, T]
$$

where $G_{t}$ is the guaranteed value at time $t$ obtained by compounding the nominal value of the contract by the minimum guarantee rate, that is

$$
G_{t}=G_{0} e^{r_{G} t} \quad t \in[0, T]
$$




\subsection{The financial market}

Consider the following dynamics for the reference fund

$$
\begin{aligned}
& d V(t)=\mu_{V} V(t) d t+\sigma_{V} V(t) d Z^{1}(t) \\
& V(0)=G_{0} .
\end{aligned}
$$

Moreover, assume that the short term interest rate evolves according to the following stochastic differential equation,

$$
\begin{aligned}
& d r(t)=\alpha\left(\mu_{r}-r(t)\right) d t+\sigma_{r} r(t) d Z^{2}(t) \\
& r(0)=r_{0} .
\end{aligned}
$$

Here, $Z^{1}(t)$ and $Z^{2}(t)$ are correlated Brownian motions, both defined on the same probability space $\left(\Omega, \mathfrak{F},\left\{\mathfrak{F}_{\mathfrak{t}}\right\}_{t \geqslant 0}, P\right)$. The correlation coefficient between $Z^{1}(t)$ and $Z^{2}(t)$ is denoted by $\rho$.

By further assuming a frictionless market where trading takes place continuously, the value of a contingent claim, $F \equiv F(t, r(t), V(t))$, written on $V$, satisfies the following partial differential equation (see Brennan and Schwartz, $1980)^{1}$

$$
\begin{array}{r}
\frac{1}{2} \sigma_{V}^{2} V^{2} F_{v v}+\frac{1}{2} \sigma_{r}^{2} r^{2} F_{r r}+\rho \sigma_{V} \sigma_{r} V r F_{v r}+V r F_{v} \\
+\left(\alpha\left(\mu_{r}-r\right)-\lambda \sigma_{r} r\right) F_{r}+F_{t}-r F=0
\end{array}
$$

where $\lambda$ is the market price of risk, which summarizes risk preferences for representative individuals. In general, $\lambda \equiv \lambda(V, t)$ is a stochastic process

\footnotetext{
${ }^{1}$ We need to further assume some smoothness and integrability conditions.
} 
depending on the value of the reference fund. However, in this paper $\lambda$ can be treated as a constant without losing generality. Solving equation (5) subject to appropriate boundary condition gives the premium of the insurance contract.

It is worth noticing that due to their analytical tractability Vasicek (Vasicek, 1977) and Cox, Ingersoll and Ross (Cox et al., 1985) models are often used to price contingent claims in economies with stochastic interest rates. However, the finite difference approach of this paper does not require great analytical manageableness. The choice of the interest-rate dynamics given in equation (4) is motivated by the better performance provided ${ }^{2}$.

\section{The policyholder's behavior}

We consider a cohort of equally-behaved policyholders. The probability that each member of the pool surrenders the contract in the interval $[t, t+d t]$, $p_{t}^{S} \equiv p_{t, d t}^{S}$, is described in terms of the hazard rate $h(t)$, that is

$$
p_{t}^{S}=1-e^{-\int_{t}^{t+d t} h(u) d u} .
$$

The policyholder's behavior is based on rational choices, so that the hazard rate depends on the difference between the amount of money that the policyholder will receive when surrendering the contract and the current value

\footnotetext{
${ }^{2}$ Chan et al. (1992) estimate a class of continuous-time models for the short rate that can be expressed within a stochastic differential equation of the type $d r(t)=$ $(a+b r(t)) d t+\sigma_{r} r(t)^{\gamma} d Z(t)$. Due to the high sensitivity of the volatility of the process to the level of $r$, they found that models with $\gamma \geqslant 1$ perform better than those with $\gamma<1$ in capturing the dynamics of the sort rate.
} 
of the contract given that the surrender option remains unexercised. Here and throughout the rest of the paper we say that it is rational to surrender at time $t$ the difference is positive at that time.

We assume that each policyholder of the pool faces proportional transaction costs $X$ which represent the fraction of the current value of the policy that the policyholder must pay if she decides to lapse. As observed in Stanton (1995), this quantity includes both monetary costs (taxes, etc...) and nonmonetary costs (inconvenience of filling out forms, etc..) that the agent incurs when abandoning the contract. These costs may also be considered as the inability of the policyholder to recognize the optimal exercise time. Note that $X$ must not be confused with the surrender charge or exit fee included in many marketed contracts.

Define on the filtered probability space, $\left(\Omega, \mathfrak{F},\left\{\mathfrak{F}_{\mathfrak{t}}\right\}_{t \geqslant 0}, P\right)$, the stochastic process $\left\{\xi_{t}\right\}_{t \geqslant 0}$ which maps each possible state of the world into the set $\{0,1\}$, where $\xi_{t}=1$ means that at time $t$ it is rational to surrender, while the reverse is intended for $\xi_{t}=0$. This stochastic process is used to determine whether lapses are rational or irrational.

Although the optimality condition described above is the main force driving the surrender process, in this model lapses might occur even if surrendering is not optimal. For instance, this could happen when the insured experiences financial difficulties. Irrational lapses are described by the parameter $\theta^{I}$, which measures the expected surrender level conditional on $\xi_{t}=0^{3}$. Thus,

\footnotetext{
${ }^{3} \mathrm{~A}$ better solution would be to let $\theta^{I}$ depend on some economic indicators giving information about the financial difficulties of the policyholders such as the unemployment rate, rather than keeping it constant (see Kim, 2005; Kuo et al., 2003). However, the introduction of such variables considerably affects the simplicity of the model, since a new source of risk that cannot be hedged away should be taken into account.
} 
the hazard rate value conditional on surrenders being irrational is

$$
h\left(t \mid \xi_{t}=0\right)=\theta^{I}
$$

and the probability of irrational lapses is

$$
p_{t}^{I}=1-e^{-\theta^{I} d_{t}}
$$

Instead, rational lapses are described by $\theta_{r_{t}}^{R} \equiv f\left(r_{t}\right)$, which depends on the current interest rate level, $r_{t}$. For a given value of $r_{t}, \theta_{r_{t}}^{R}$ measures the speed of surrenders when $\xi_{t}=1$. A value of $\theta_{r_{t}}^{R}$ equal to infinity makes all policyholders lapse the contract as soon as they recognize that it is rational (by ignoring irrational lapses, this is the case described by the American Option Pricing theory). Conversely, a value of $\theta_{r_{t}}^{R}$ equal to zero means that rational lapses never occur. In the middle of these two extremes, the higher the value of $\theta_{r}^{R}$, the more likely the lapse takes place. The hazard rate value when lapses are rational is

$$
h\left(t \mid \xi_{t}=1\right)=\theta_{r_{t}}^{R}+\theta^{I},
$$

while the probability of rational lapses is

$$
p_{t}^{R}=1-e^{-\left[\theta_{r_{t}}^{R}+\theta^{I}\right] d t} .
$$

Remark 1 We observe that equations (6) and (8) address not only the relationship between the lapse rate intensity and the short rate, but also 
the relationship between $h(t)$ and the reference fund, $V(t)$, through the stochastic process $\left\{\xi_{t}\right\}_{t \geqslant 0}$.

Remark 2 Equation (8) highlights the fact that irrational surrenders do not depend on the current value of the contract and thus they must be taken into account even when it is rational to abandon the contract.

Rational surrenders depend on the level of the prevailing interest rate in the market. In periods of high interest rates, it is more likely that policyholders lapse the contract, since they probably may switch to more attractive forms of investment. We model the dependence of $\theta_{r_{t}}^{R}$ on the interest rate through the following relation

$$
\theta_{r_{t}}^{R}=A^{2} r_{t}^{2}+B
$$

with $A, B \geqslant 0$. The parameter $A$ describes the sensibility of the policyholders' behavior with respect to the current interest rate level. When $A=0$, the lapse probability solely depends on $B$, which in turn may be considered as a scale parameter.

Remark 3 The choice of a quadratic function to describe the relationship between $\theta_{r_{t}}^{R}$ and the short rate is motivated by simplicity reasons. However, any increasing function of the short rate might in principle be suitable.

Figure 1 shows the probability of rational lapses we would have observed during the period January/2000-April/2007 for three different choices of $A$. The 3-month US Treasury Bill rate is the reference interest rate. To summarize, the hazard function $h(t)$ describing the likelihood of lapses in any given 


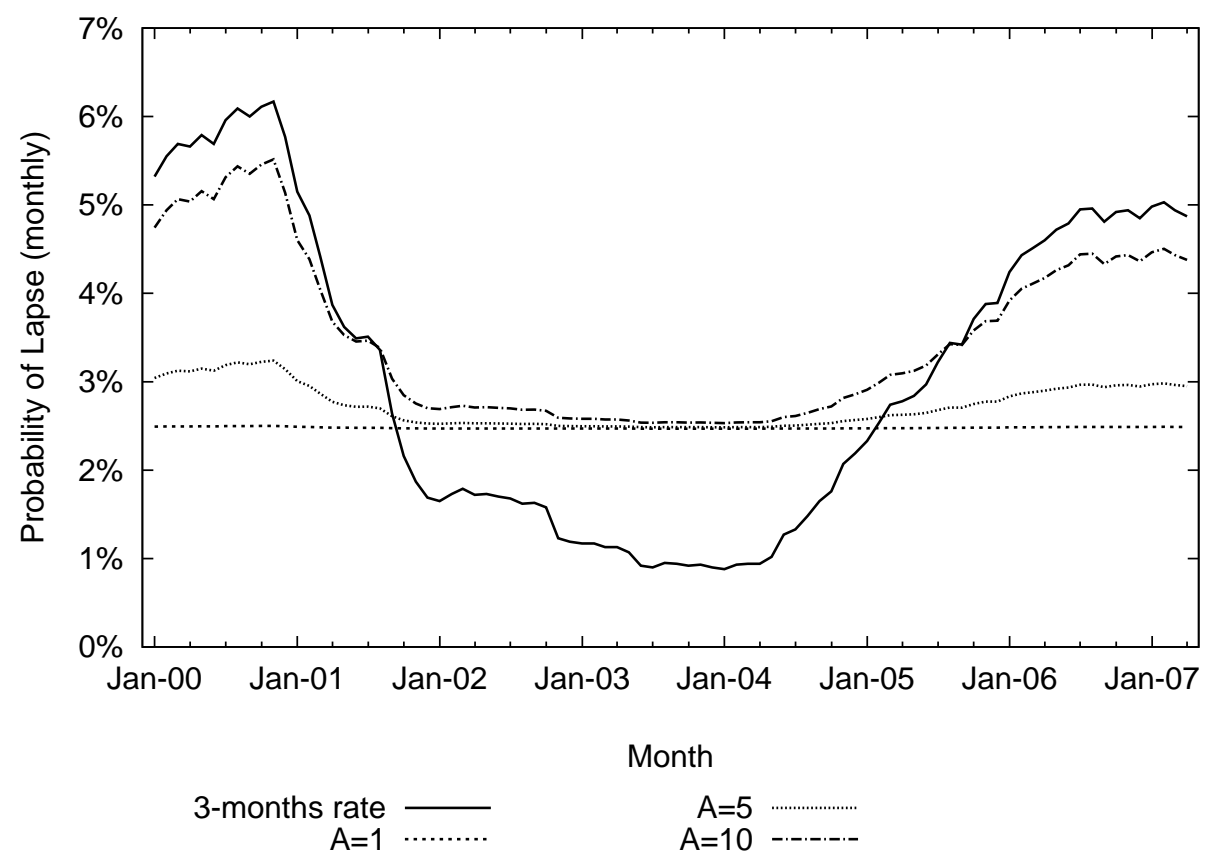

Figure 1: In this example, irrational surrenders are ignored. Parameter $A$ determines the sensibility of the lapse probability with respect to the market rate. For low values of $A$, the probability of surrender is largely determined on parameter $B$, which also contributes to determining the lowest lapse probability. As $A$ increases, a shift in the interest rate highly affects the lapse probability.

time $t$ is given by ${ }^{4}$

$$
h(t)=\theta^{I} \mathbb{1}_{\left\{\xi_{t}=0\right\}}+\left(\theta^{I}+A^{2} r^{2}+B\right) \mathbb{1}_{\left\{\xi_{t}=1\right\}} .
$$

\subsection{The case of heterogenous pools}

So far we have considered the behavior of homogenous cohorts of policyholders. The price of a pool of policies where all insured are assumed to be identical (that is all facing the same transaction cost) is straightforward.

\footnotetext{
${ }^{4} \mathbb{1}_{\chi}(x)$ is the indicator function of $\chi$.
} 
However, a pool of policies generally groups people that cannot be considered equal. In this rational expectation model, heterogeneity in the pool can be easily considered by introducing a probability distribution for initial transaction costs. For instance, we can consider a beta distribution. The density function of a random variable $X$ which is beta-distributed with parameter $a$ and $b$ is

$$
f_{X}(s)= \begin{cases}\frac{y^{a-1}(1-s)^{b-1}}{B(a, b)} & 0<s<1 \\ 0 & \text { otherwise }\end{cases}
$$

where $B(a, b)$ is the beta function,

$$
B(a, b)=\int_{0}^{1} v^{a-1}(1-v)^{b-1} d v .
$$

\section{Valuation}

In this section, we will consider the partial differential equation that appears in equation (5) and describe the practical implementation of the model.

Equation (5) describes a parabolic partial differential equation which can be solved by applying a finite difference method. The use of a finite difference approximation entails the replacement of the derivatives appearing in equation (5) with equations involving the values of both the asset and the short rate at neighboring points on a discrete three-dimensional grid of $V, r$ and $t$ values.

Starting from the boundary condition which characterizes the benefit at 
maturity, $F(T, r(T), V(T))=B(T)$, a finite difference method works backwards to solve equation (5) one step at a time and to compute the value of the contract. This gives the value of the company's liability if the put option remains unexercised, $F^{C}\left(t^{*}, r^{*}, V^{*}\right)$ - referred as the continuation value, in the point $\left(t^{*}, r^{*}, V^{*}\right)$ of the three-dimensional grid.

In the case we consider the contract as an American contingent claim, we must apply the following boundary condition characterizing the American feature of the option ${ }^{5}$,

$$
F\left(t^{*}, r^{*}, V^{*}\right)= \begin{cases}F^{C}\left(t^{*}, r^{*}, V^{*}\right) & F^{C}\left(t^{*}, r^{*}, V^{*}\right) \geqslant B\left(t^{*}, V^{*}\right) \\ B\left(t^{*}, V^{*}\right) & \text { otherwise. }\end{cases}
$$

Equation (11) indicates that policyholders are able to optimally exercise the option at any time during the contract's life.

Conversely, in the case of the rational expectation model described in section 3, the new boundary condition is as follows (suppressing the dependence on $r^{*}$ and $V^{*}$ for clear references),

$$
F\left(t^{*}\right)= \begin{cases}p_{t^{*}}^{I} B_{t^{*}}+\left(1-p_{t^{*}}^{I}\right) F^{C}\left(t^{*}\right) & F^{C}\left(t^{*}\right) \geqslant B\left(t^{*}\right)(1-X) \\ p_{t^{*}}^{R} B\left(t^{*}\right)+\left(1-p_{t^{*}}^{R}\right) F^{C}\left(t^{*}\right) & \text { otherwise. }\end{cases}
$$

Equation (12) characterizes the policyholders' behavior in the following way: They compare the value of the contract conditional on the put option remaining unexercised, $F^{C}\left(t^{*}\right)$, with the value of the contract they would obtain if they decide to lapse the contract at time $t^{*}, B\left(t^{*}\right)(1-X)$; if they

\footnotetext{
${ }^{5}$ See (Brennan and Schwartz, 1977).
} 
do not find it optimal to abandon the contract, that is $F^{C}\left(t^{*}\right) \geqslant B\left(t^{*}\right)(1-X)$, then

i. they might lapse the contract for exogenous reasons with probability $p_{t^{*}}^{I}$. In this case the insurer's liability is $B\left(t^{*}\right)$.

ii. they might continue the contract with probability $\left(1-p_{t^{*}}^{I}\right)$. In this case the insurer liability is $F^{C}\left(t^{*}\right)$.

Conversely, if the policyholder find it optimal to lapse the contract, that is $F^{C}\left(t^{*}\right)<B\left(t^{*}\right)(1-X)$, then

i. they might lapse the contract optimally with probability $p_{t^{*}}^{R}$. In this case the insurer's liability is $B\left(t^{*}\right)$.

ii. they might continue the contract with probability $\left(1-p_{t^{*}}^{R}\right)$. In this case the insurer liability equals the continuation value, $F^{C}\left(t^{*}\right)$.

\section{$5 \quad$ Numerical Examples}

This section provides some selected numerical experiments showing the peculiarities of the model proposed in this paper, with respect to the American Contingent Claim approach.

As the first step of our analysis, we compare the values of the surrender options resulting from the RE model with those derived from the ACC theory. Tables 1 and 2 show the surrender option values, defined as difference between the value of the contract which includes the surrender condition and the value of the non-exercisable contract (i.e. its European version), for different 
maturities and minimum guaranteed rates of return. Looking at these two tables, the first thing to be noticed is that ACC always provides higher values. This is not surprising since by definition the ACC theory gives an upper bound for the surrender option, since it provides the strategy which maximizes the profit for the policyholder value and, then, the liability of the insurance company.

Although the two approaches show the same pattern, it is to be noticed that for short maturities the relative difference between the two approaches is much bigger. For instance, in Table 1 ACC provides prices which are almost twice the prices given by the Rational Expectation model, when the maturity is two 2 years, and this occurs in Table 2 as well (notice that the two tables are computed with all the parameters being equal except for those governing the dynamics of the interest rate process).

To give a more complete picture of the situation, we have also examined the sensitivity of the value of the liabilities with respect to shocks in the short rate. Following Briys and de Varenne (1997), we define the elasticity, $\eta$, of the contract value as the negative of the relative change of the contract value with respect to infinitesimal changes in the interest rate, that is:

$$
\eta=-\frac{1}{F(t, V(t))} \frac{\partial F(t, V(t))}{\partial r_{t}}
$$

This quantity affects both the duration and the convexity of the insurance product, which constitute the basis for a classic Asset and Liability Management (ALM) system (see Briys and de Varenne, 1997). Figures 2 and 3 depict the elasticity of the contract prices against the time to maturity 


\begin{tabular}{|c|c|c|c|c|c|c|}
\hline \multirow[b]{2}{*}{$r_{G}$} & \multicolumn{6}{|c|}{ Time to maturity (Years) } \\
\hline & 1 & 2 & 5 & 10 & 15 & 20 \\
\hline $0 \%$ & $\begin{array}{c}1.287 \\
(3.096)\end{array}$ & $\begin{array}{c}2.485 \\
(4.152)\end{array}$ & $\begin{array}{c}4.563 \\
(5.904)\end{array}$ & $\begin{array}{c}6.007 \\
(7.219)\end{array}$ & $\begin{array}{c}6.618 \\
(7.778)\end{array}$ & $\begin{array}{l}6.902 \\
(8.02)\end{array}$ \\
\hline $0.5 \%$ & $\begin{array}{c}1.32 \\
(3.172)\end{array}$ & $\begin{array}{c}2.585 \\
(4.269)\end{array}$ & $\begin{array}{c}4.83 \\
(6.127)\end{array}$ & $\begin{array}{c}6.503 \\
(7.655)\end{array}$ & $\begin{array}{c}7.304 \\
(8.395)\end{array}$ & $\begin{array}{c}7.729 \\
(8.787)\end{array}$ \\
\hline $1 \%$ & $\begin{array}{c}1.355 \\
(3.256)\end{array}$ & $\begin{array}{c}2.685 \\
(4.667)\end{array}$ & $\begin{array}{c}5.121 \\
(6.389)\end{array}$ & $\begin{array}{c}7.018 \\
(8.106)\end{array}$ & $\begin{array}{c}8.028 \\
(9.049)\end{array}$ & $\begin{array}{c}8.625 \\
(9.603)\end{array}$ \\
\hline $1.5 \%$ & $\begin{array}{c}1.39 \\
(3.347)\end{array}$ & $\begin{array}{c}2.79 \\
(4.533)\end{array}$ & $\begin{array}{l}5.389 \\
(6.63)\end{array}$ & $\begin{array}{c}7.541 \\
(8.563)\end{array}$ & $\begin{array}{c}8.768 \\
(9.716)\end{array}$ & $\begin{array}{c}9.568 \\
(10.469)\end{array}$ \\
\hline $2 \%$ & $\begin{array}{c}1.427 \\
(3.446)\end{array}$ & $\begin{array}{c}2.896 \\
(4.695)\end{array}$ & $\begin{array}{c}5.688 \\
(6.917)\end{array}$ & $\begin{array}{l}8.076 \\
(9.04)\end{array}$ & $\begin{array}{c}9.524 \\
(10.398)\end{array}$ & $\begin{array}{c}10.537 \\
(11.359)\end{array}$ \\
\hline $2.5 \%$ & $\begin{array}{l}1.465 \\
(3.57)\end{array}$ & $\begin{array}{c}3.004 \\
(4.887)\end{array}$ & $\begin{array}{c}6.009 \\
(7.249)\end{array}$ & $\begin{array}{c}8.639 \\
(9.556)\end{array}$ & $\begin{array}{c}10.297 \\
(11.102)\end{array}$ & $\begin{array}{c}11.523 \\
(12.268)\end{array}$ \\
\hline $3 \%$ & $\begin{array}{l}1.502 \\
(3.71)\end{array}$ & $\begin{array}{c}3.119 \\
(5.115)\end{array}$ & $\begin{array}{c}6.361 \\
(7.652)\end{array}$ & $\begin{array}{c}9.262 \\
(10.158)\end{array}$ & $\begin{array}{c}10.127 \\
(10.883)\end{array}$ & $\begin{array}{c}12.551 \\
(13.232)\end{array}$ \\
\hline $3.5 \%$ & $\begin{array}{c}1.544 \\
(3.877)\end{array}$ & $\begin{array}{l}3.242 \\
(5.39)\end{array}$ & $\begin{array}{c}6.759 \\
(8.163)\end{array}$ & $\begin{array}{c}10.002 \\
(10.929)\end{array}$ & $\begin{array}{c}12.11 \\
(12.858)\end{array}$ & $\begin{array}{c}13.74 \\
(14.39)\end{array}$ \\
\hline $4 \%$ & $\begin{array}{c}1.586 \\
(4.081)\end{array}$ & $\begin{array}{c}3.368 \\
(5.742)\end{array}$ & $\begin{array}{c}7.217 \\
(8.853)\end{array}$ & $\begin{array}{c}10.962 \\
(12.042)\end{array}$ & $\begin{array}{c}13.462 \\
(14.313)\end{array}$ & $\begin{array}{c}15.415 \\
(16.136)\end{array}$ \\
\hline $4.5 \%$ & $\begin{array}{c}1.63 \\
(4.332)\end{array}$ & $\begin{array}{c}3.503 \\
(6.231)\end{array}$ & $\begin{array}{c}7.755 \\
(9.902)\end{array}$ & $\begin{array}{c}12.3 \\
(13.982)\end{array}$ & $\begin{array}{c}15.652 \\
(17.153)\end{array}$ & $\begin{array}{c}18.479 \\
(19.525)\end{array}$ \\
\hline $5 \%$ & $\begin{array}{c}1.675 \\
(4.611)\end{array}$ & $\begin{array}{c}3.647 \\
(6.798)\end{array}$ & $\begin{array}{c}8.38 \\
(11.36)\end{array}$ & $\begin{array}{c}14.101 \\
(17.073)\end{array}$ & $\begin{array}{c}18.945 \\
(22.082)\end{array}$ & $\begin{array}{c}23.487 \\
(26.813)\end{array}$ \\
\hline
\end{tabular}

Table 1: The value of the surrender option in the case of Rational Expectation setting against the American Contingent Claim theory approach (in parenthesis). The following parametrization has been used: $G_{0}=100, r_{0}=0.035$, $\sigma=0.1, \sigma_{r}=0.09, \alpha=0.6, \mu_{r}=0.045, \rho=-0.4, \delta^{M}=\delta^{S}=1$ and $r_{G}^{M}=r_{G}^{S}=r_{G}$, while the policyholders' behavior is described by the triple $A=5, B=0.2, \theta^{I}=0.4$. No transaction costs are assumed. 


\begin{tabular}{|c|c|c|c|c|c|c|}
\hline \multirow[b]{2}{*}{$r_{G}$} & \multicolumn{6}{|c|}{ Time to maturity (Years) } \\
\hline & 1 & 2 & 5 & 10 & 15 & 20 \\
\hline $0 \%$ & $\begin{array}{c}1.31 \\
(3.174)\end{array}$ & $\begin{array}{c}2.585 \\
(4.286)\end{array}$ & $\begin{array}{c}4.958 \\
(6.283)\end{array}$ & $\begin{array}{l}6.852 \\
(8.04)\end{array}$ & $\begin{array}{c}7.675 \\
(8.813)\end{array}$ & $\begin{array}{c}8.015 \\
(9.112)\end{array}$ \\
\hline $0.5 \%$ & $\begin{array}{c}1.342 \\
(3.262)\end{array}$ & $\begin{array}{c}2.687 \\
(4.414)\end{array}$ & $\begin{array}{c}5.249 \\
(6.542)\end{array}$ & $\begin{array}{c}7.439 \\
(8.569)\end{array}$ & $\begin{array}{c}8.523 \\
(9.6)\end{array}$ & $\begin{array}{c}9.043 \\
(10.083)\end{array}$ \\
\hline $1 \%$ & $\begin{array}{l}1.377 \\
(3.357)\end{array}$ & $\begin{array}{c}2.79 \\
(4.562)\end{array}$ & $\begin{array}{c}5.549 \\
(6.821)\end{array}$ & $\begin{array}{c}8.043 \\
(9.116)\end{array}$ & $\begin{array}{c}9.425 \\
(10.44)\end{array}$ & $\begin{array}{c}10.181 \\
(11.159)\end{array}$ \\
\hline $1.5 \%$ & $\begin{array}{l}1.415 \\
(3.464)\end{array}$ & $\begin{array}{c}2.895 \\
(4.734)\end{array}$ & $\begin{array}{c}5.864 \\
(7.132)\end{array}$ & $\begin{array}{c}8.668 \\
(9.689)\end{array}$ & $\begin{array}{c}10.371 \\
(11.324)\end{array}$ & $\begin{array}{c}11.417 \\
(12.333)\end{array}$ \\
\hline $2 \%$ & $\begin{array}{c}1.454 \\
(3.583)\end{array}$ & $\begin{array}{c}3.006 \\
(4.935)\end{array}$ & $\begin{array}{c}6.203 \\
(7.491)\end{array}$ & $\begin{array}{c}9.323 \\
(10.302)\end{array}$ & $\begin{array}{c}11.356 \\
(12.253)\end{array}$ & $\begin{array}{c}12.732 \\
(13.587)\end{array}$ \\
\hline $2.5 \%$ & $\begin{array}{c}1.494 \\
(3.728)\end{array}$ & $\begin{array}{c}3.122 \\
(5.177)\end{array}$ & $\begin{array}{c}6.575 \\
(7.924)\end{array}$ & $\begin{array}{c}10.032 \\
(10.99)\end{array}$ & $\begin{array}{c}12.392 \\
(13.244)\end{array}$ & $\begin{array}{c}14.116 \\
(14.92)\end{array}$ \\
\hline $3 \%$ & $\begin{array}{c}1.533 \\
(3.901)\end{array}$ & $\begin{array}{c}3.244 \\
(5.475)\end{array}$ & $\begin{array}{c}6.993 \\
(8.473)\end{array}$ & $\begin{array}{c}10.838 \\
(11.816)\end{array}$ & $\begin{array}{c}13.524 \\
(14.356)\end{array}$ & $\begin{array}{c}15.591 \\
(16.362)\end{array}$ \\
\hline $3.5 \%$ & $\begin{array}{c}1.576 \\
(4.126)\end{array}$ & $\begin{array}{c}3.373 \\
(5.868)\end{array}$ & $\begin{array}{c}7.473 \\
(9.212)\end{array}$ & $\begin{array}{c}11.815 \\
(12.897)\end{array}$ & $\begin{array}{c}14.857 \\
(15.722)\end{array}$ & $\begin{array}{c}17.256 \\
(18.033)\end{array}$ \\
\hline $4 \%$ & $\begin{array}{c}1.618 \\
(4.394)\end{array}$ & $\begin{array}{c}3.509 \\
(6.381)\end{array}$ & $\begin{array}{c}8.029 \\
(10.263)\end{array}$ & $\begin{array}{c}13.067 \\
(14.458)\end{array}$ & $\begin{array}{c}16.591 \\
(17.626)\end{array}$ & $\begin{array}{c}19.364 \\
(20.242)\end{array}$ \\
\hline $4.5 \%$ & $\begin{array}{c}1.663 \\
(4.672)\end{array}$ & $\begin{array}{c}3.653 \\
(6.963)\end{array}$ & $\begin{array}{c}8.668 \\
(11.66)\end{array}$ & $\begin{array}{c}14.677 \\
(16.77)\end{array}$ & $\begin{array}{l}18.993 \\
(20.55)\end{array}$ & $\begin{array}{c}22.373 \\
(23.646)\end{array}$ \\
\hline $5 \%$ & $\begin{array}{c}1.708 \\
(4.963)\end{array}$ & $\begin{array}{c}3.807 \\
(7.583)\end{array}$ & $\begin{array}{c}9.389 \\
(13.315)\end{array}$ & $\begin{array}{c}16.671 \\
(19.931)\end{array}$ & $\begin{array}{c}22.239 \\
(24.917)\end{array}$ & $\begin{array}{c}26.743 \\
(29.053)\end{array}$ \\
\hline
\end{tabular}

Table 2: The value of the surrender option in the case of Rational Expectation setting against the American Contingent Claim theory approach (in parenthesis). The following parametrization has been used: $G_{0}=100, r_{0}=0.035$, $\sigma=0.1, \sigma_{r}=0.09, \alpha=0.1, \mu_{r}=0.06, \rho=-0.4, \delta^{M}=\delta^{S}=1$ and $r_{G}^{M}=r_{G}^{S}=r_{G}$, while the policyholders' behavior is described by the triple $A=5, B=0.2, \theta^{I}=0.4$. No transaction costs are assumed. 
for two different dynamics of the short rate. Once again the shorter is the maturity, the higher is the difference between the elasticities provided by the two approaches. Thus, the introduction of a rational behavior for policyholders surrendering the contract has a stronger impact on the ALM system as the contract approaches maturity.

We now turn to look at the effect of policyholders' behavior on the value of the contract. Figure 4 plots the price of the surrender option for different combinations of parameters $A$ and $B$. Recall that these two parameters control the intensity of rational lapses, $\theta_{r_{t}}^{R}$ (see equation (10)). When $A=0$, $\theta_{r_{t}}^{R}$ is interest rate-independent, meaning that rational lapses are at the same level for different values of the observed short rate. Figure 4 shows that the surrender option prices tend to reach their maximum value (the price provided by $\mathrm{ACC}$ ) as the value of $B$ increases. This also happens for positive values of $A$. For low levels of $B$, we also observe remarkable differences for the various levels of $A$.

In order to capture some insights concerning the effect of irrational surrenders, in Table 3 we report surrender option prices for different levels of maturities and values of $\theta^{I}$. We recall that $\theta^{I}$ measures the intensity of irrational lapses. A value of $\theta^{I}$ equal to zero means that no irrational abandons occur. We assumed the maximum annual level of $\theta^{I}$ to be equal to three, which corresponds to a probability of irrational abandons of $p^{I}=95 \%$ per year. Table 3 shows that a change in the intensity of irrational lapses may dramatically affect the value of the surrender option. On the other hand, ACC theory completely ignores irrational abandons. We investigated this phenomena further to check whether the interest rate elasticities of the con- 


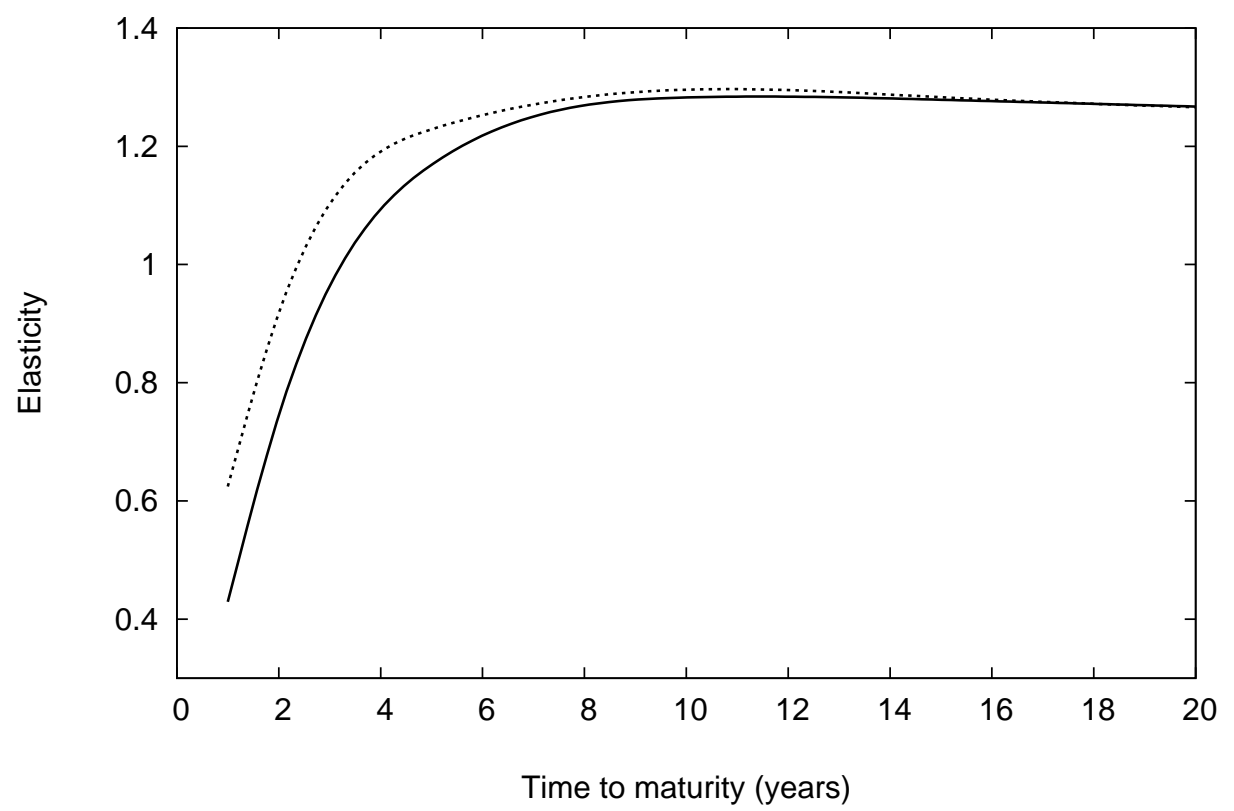

Rational Expectations

American Option Pricing

Figure 2: Comparison of elasticity values of the contract embedding the surrender option. The following parametrization has been used: $G_{0}=100$, $r_{0}=0.035, \sigma=0.1, \sigma_{r}=0.09, \alpha=0.6, \mu_{r}=0.045, \rho=-0.4, \delta^{M}=\delta^{S}=1$ and $r_{G}^{M}=r_{G}^{S}=3.5 \%$, while the policyholders' behavior is described by the triple $A=5, B=0.2, \theta^{I}=0.4$. No transaction costs are assumed.

tract prices are also affected by irrational surrenders. Figure 5 shows the influence of $\theta^{I}$ on the elasticity. It is important to observe that the differences might be considerably high, and that irrational surrenders affect the elasticity also for long-term maturities.

\section{Concluding Remarks}

The valuation of the surrender option can be accomplished either by the use of a statistical model that fits the observed lapse data or by the use of the American option pricing theory. The use of the first approach has good 


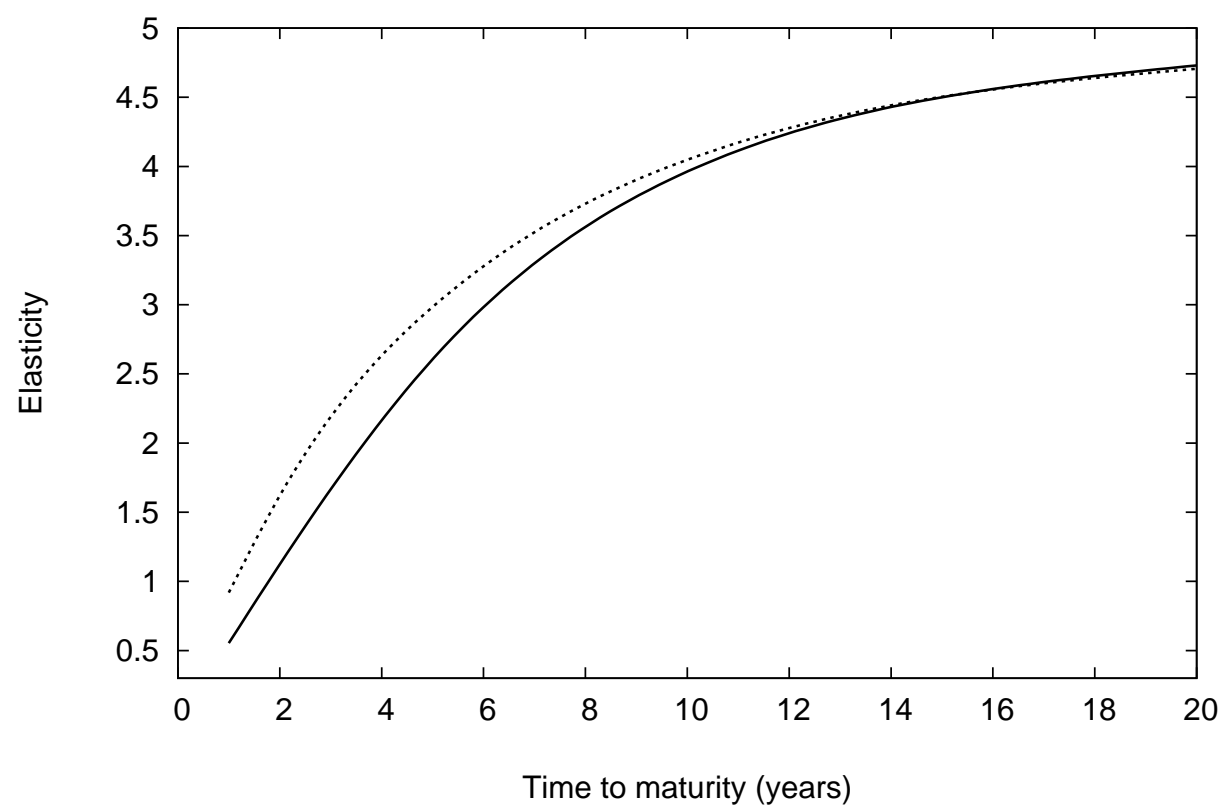

Rational Expectations

American Option Pricing

Figure 3: Comparison of elasticity values of the contract embedding the surrender option. The following parametrization has been used: $G_{0}=100$, $r_{0}=0.035, \sigma=0.1, \sigma_{r}=0.09, \alpha=0.1, \mu_{r}=0.06, \rho=-0.4, \delta^{M}=\delta^{S}=1$ and $r_{G}^{M}=r_{G}^{S}=3.5 \%$, while the policyholders' behavior is described by the triple $A=5, B=0.2, \theta^{I}=0.4$. No transaction costs are assumed.

characteristics in terms of goodness of fit of the statistical model with the data observed, but has great disadvantages in terms of pricing. On the other hand, the American option pricing theory provides a powerful tool for pricing the surrender option, but cannot explain the data observed.

Recent research papers perform statistical analyses relating the lapse rate to economic variables such as the unemployment rate or the economic growth rate. In particular, Kuo et al. (2003) find that in U. S. there exists a relationship between the lapse rate, the interest rate and the unemployment rate. Further, they suggest the need for either a general equilibrium model or a rational expectation model to address their findings. 


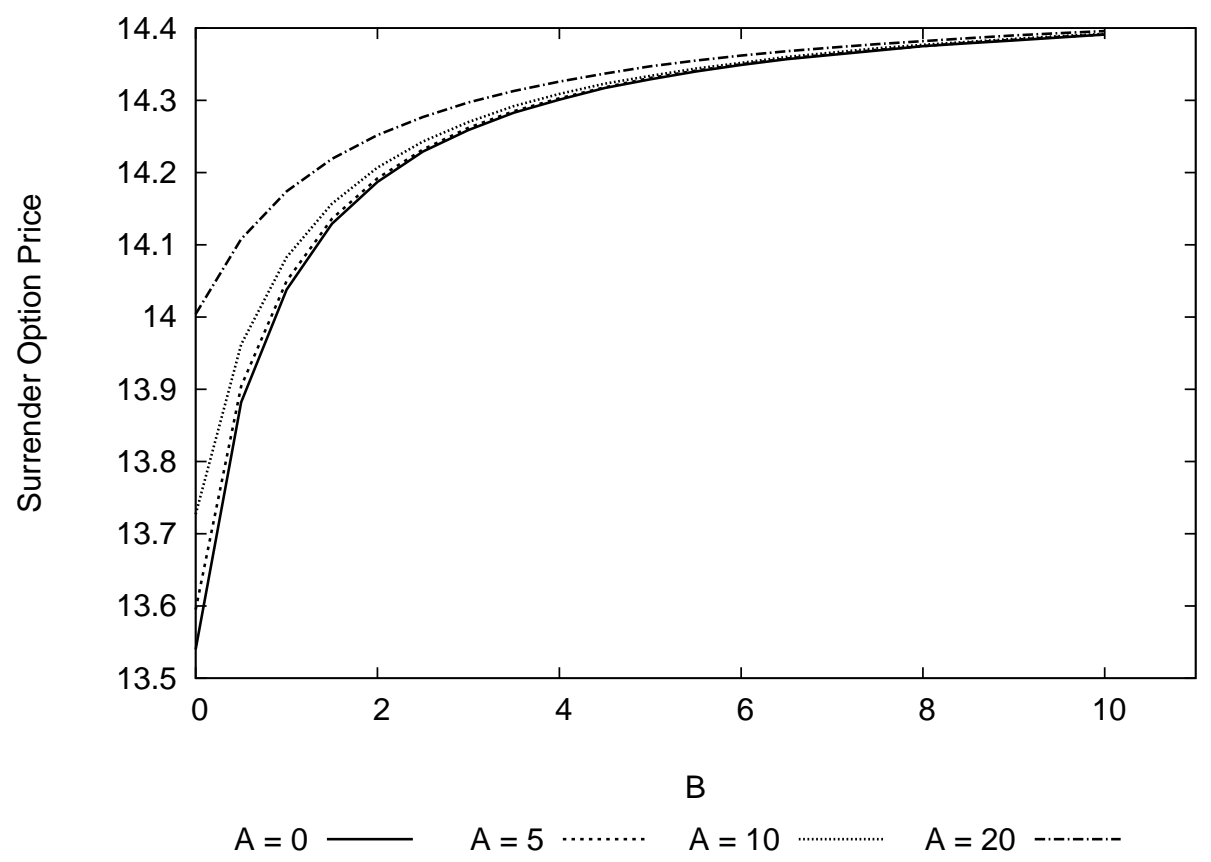

Figure 4: The effect of different policyholders behavior on the values of the surrender option. The following parametrization has been used: $G_{0}=100$, $r_{0}=0.035, \sigma=0.1, \sigma_{r}=0.09, \alpha=0.1, \mu_{r}=0.06, \rho=-0.4, \delta^{M}=\delta^{S}=1$ and $r_{G}^{M}=r_{G}^{S}=3.5 \%, T=20$ years, $\theta^{I}=0.4$. No transaction costs are assumed.

In this paper, we have built a Rational Expectation model that can be viewed as the link between the statistical approach and the option pricing method. As in Stanton (1995), the policyholders' behavior proposed in this model has been divided into a rational component driven by the prevailing interest rate market, and an irrational part.

We found that the rational component affects the price of the surrender options and the interest-rate elasticity mainly in the short term, while the irrational component may have a considerable impact both in the short and long term.

Our results suggest further investigation into the irrational component of 


\begin{tabular}{cccccccc} 
& \multicolumn{7}{c}{$\theta^{I}$} \\
\cline { 2 - 8 } Maturity & 0 & 0.5 & 1 & 1.5 & 2 & 2.5 & 3 \\
\hline \hline 1 & 0.362 & 1.517 & 2.114 & 2.46 & 2.682 & 2.833 & 2.942 \\
2 & 1.061 & 2.979 & 3.646 & 3.961 & 4.139 & 4.251 & 4.329 \\
5 & 3.436 & 5.684 & 6.135 & 6.319 & 6.418 & 6.481 & 6.524 \\
10 & 7.019 & 8.745 & 9.041 & 9.165 & 9.233 & 9.277 & 9.306 \\
15 & 10.194 & 11.582 & 11.826 & 11.929 & 11.986 & 12.022 & 12.047 \\
20 & 13.008 & 14.211 & 14.428 & 14.52 & 14.571 & 14.603 & 14.625 \\
\hline
\end{tabular}

Table 3: The effect of irrational lapses on the values of the surrender option. The following parametrization has been used: $G_{0}=100, r_{0}=0.035, \sigma=0.1$, $\sigma_{r}=0.09, \alpha=0.1, \mu_{r}=0.06, \rho=-0.4, \delta^{M}=\delta^{S}=1$ and $r_{G}^{M}=r_{G}^{S}=3.5 \%$, $A=10, B=0.2$. No transaction costs are assumed.

the policyholder behavior. More precisely, here we address the need for a more realistic model where irrational abandons are linked to some economic variables such as unemployment rate. This is a promising future field of exploration.

Many other directions for further research emerge. First, the extension to the periodic premium case and the introduction of mortality would be a natural objective to pursue. Second, a computational tool for the pricing of more sophisticated products such as participating policies is needed. To accomplish this objective, a combination of the Alternating Direction Implicit method described in Appendix A and the finite difference method proposed by Jensen et al. (2001) could be used. Finally, it could be interesting to see how credit risk and regulatory constraints affect the surrender level. 


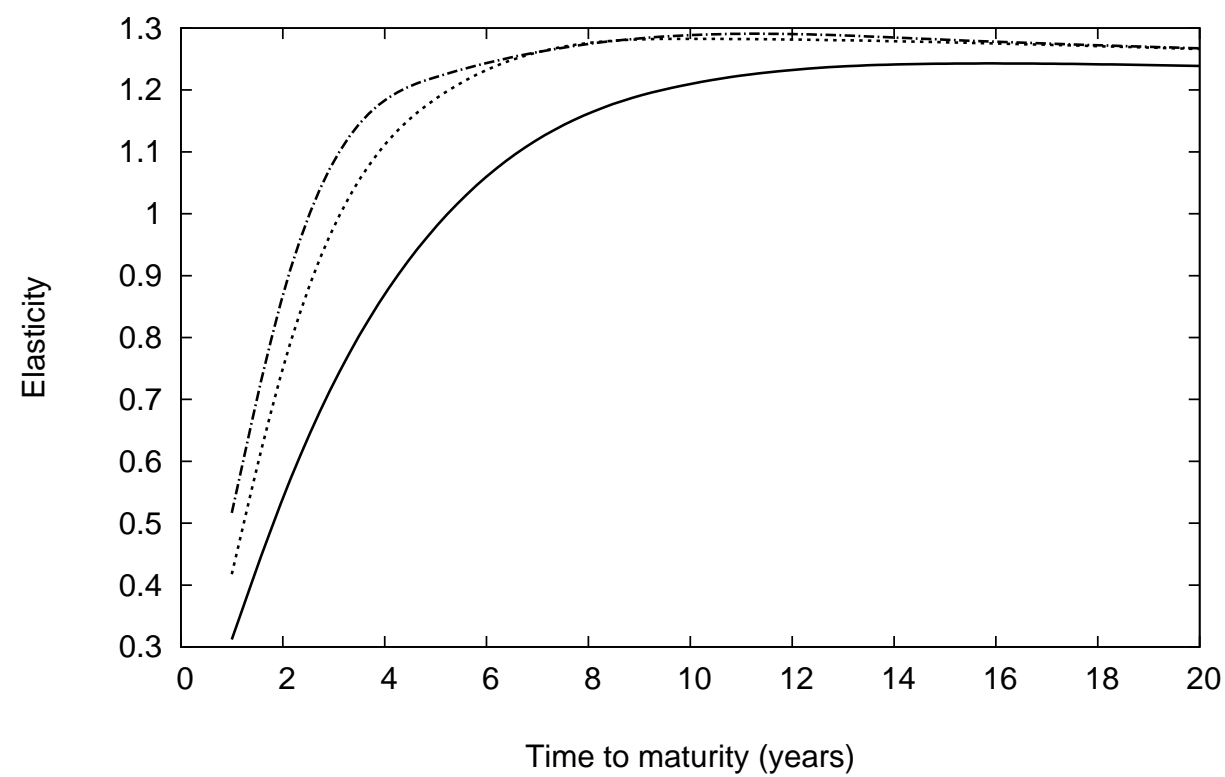

Irrational intensity $=0.0$ Irrational intensity $=0.5$

Irrational intensity $=3.0$

Figure 5: The effect of irrational surrenders on the sensitivity of the contract with respect to the interest rate. The following parametrization has been used: $G_{0}=100, r_{0}=0.035, \sigma=0.1, \sigma_{r}=0.09, \alpha=0.1, \mu_{r}=0.06$, $\rho=-0.4, \delta^{M}=\delta^{S}=1$ and $r_{G}^{M}=r_{G}^{S}=3.5 \%, A=10, B=0.2$. No transaction costs are assumed.

\section{A The finite difference scheme}

We first transform equation (5) in a way that facilitates the implementation and improves the stability and the accuracy of the finite difference method. Thus, by making the changes of variables $x_{1}=\ln (V)$ and $x_{2}=\ln (r)$ and $F(V, r, t) \equiv G\left(x_{1}(V), x_{2}(r), t\right)$, equation (5) becomes:

$$
\begin{array}{r}
0=\frac{\sigma_{V}^{2}}{2} \frac{\partial^{2} G}{\partial x_{1}^{2}}+\frac{\sigma_{r}^{2}}{2} \frac{\partial^{2} G}{\partial x_{2}^{2}}+\rho \sigma_{V} \sigma_{r} \frac{\partial^{2} G}{\partial x_{1} x_{2}}+\nu_{1}\left(x_{2}\right) \frac{\partial G}{\partial x_{1}} \\
+\nu_{2}\left(x_{2}\right) \frac{\partial G}{\partial x_{2}}+\frac{\partial G}{\partial t}-\nu_{3}\left(x_{2}\right) G
\end{array}
$$


where

$$
\begin{aligned}
& \nu_{1}\left(x_{2}\right)=\exp \left(x_{2}\right)-\frac{\sigma_{V}^{2}}{2} \\
& \nu_{2}\left(x_{2}\right)=\alpha\left(\exp \left(-x_{2}\right) \mu_{r}-1\right)-\sigma_{r}\left(\lambda+\frac{\sigma_{r}}{2}\right) \\
& \nu_{3}\left(x_{2}\right)=\exp \left(x_{2}\right) .
\end{aligned}
$$

Variables $x_{1}$ and $x_{2}$ are then rotated in order to obtain two new variables, $y_{1}$ and $y_{2}$, which are uncorrelated under the new space. Let $\gamma_{1}$ and $\gamma_{2}$ be the eigenvalues of the covariance matrix

$$
\Sigma=\left(\begin{array}{cc}
\sigma_{V}^{2} & \rho \sigma_{V} \sigma_{r} \\
\rho \sigma_{V} \sigma_{r} & \sigma_{r}^{2}
\end{array}\right)
$$

and $e_{1}=\left(e_{11}, e_{12}\right)^{T}$ and $e_{2}=\left(e_{21}, e_{22}\right)^{T}$ some corresponding eigenvectors ${ }^{6}$. We define the new variables as follows:

$$
\begin{aligned}
y_{1} & =e_{11} x_{1}+e_{12} x_{2} \\
y_{2} & =e_{21} x_{1}+e_{22} x_{2} \\
d y_{1} & =\widetilde{\nu}_{1}\left(y_{1}, y_{2}\right) d t+\sqrt{\gamma_{1}} d W^{1}(t) \\
d y_{2} & =\widetilde{\nu}_{2}\left(y_{1}, y_{2}\right) d t+\sqrt{\gamma_{2}} d W^{2}(t) \\
\widetilde{\nu}_{1}\left(y_{1}, y_{2}\right) & =e_{11} \nu_{1}\left(x_{2}\right)+e_{12} \nu_{2}\left(x_{2}\right) \\
\widetilde{\nu}_{2}\left(y_{1}, y_{2}\right) & =e_{21} \nu_{1}\left(x_{2}\right)+e_{22} \nu_{2}\left(x_{2}\right)
\end{aligned}
$$

where $W^{1}(t)$ and $W^{2}(t)$ are uncorrelated Brownian motions. Under this ${ }^{6} e^{T}$ denotes the transpose of $e$. 
transformation, equation (5) becomes:

$$
\begin{array}{r}
0=\frac{\gamma_{1}}{2} \frac{\partial^{2} G}{\partial y_{1}^{2}}+\frac{\gamma_{2}}{2} \frac{\partial^{2} G}{\partial y_{2}^{2}}+\widetilde{\nu}_{1}\left(y_{1}, y_{2}\right) \frac{\partial G}{\partial y_{1}}+\widetilde{\nu}_{2}\left(y_{1}, y_{2}\right) \frac{\partial G}{\partial y_{2}}+ \\
\frac{\partial G}{\partial t}-\widetilde{\nu}_{3}\left(y_{1}, y_{2}\right) G
\end{array}
$$

where $\widetilde{\nu}_{1}\left(y_{1}, y_{2}\right), \widetilde{\nu}_{2}\left(y_{1}, y_{2}\right)$ and $\widetilde{\nu}_{3}\left(y_{1}, y_{2}\right)$ are explicitly determined but omitted to avoid further complications.

Having introduced the necessary simplifications, we now shift our attention to the approximation of the partial differential equation (A.6) by a finite difference scheme. Let $h_{1}, h_{2}$ and $k$ be the step lengths in the $y_{1}, y_{2}$ and $t$ dimensions respectively. We replace the region

$$
\Xi \equiv\left\{\left(y_{1}, y_{2}, t\right): y_{1} \in\left[y_{1}^{\min }, y_{1}^{\max }\right], y_{2} \in\left[y_{2}^{\min }, y_{2}^{\max }\right], t \in[0, T]\right\}
$$

where equation (A.6) is defined by a set of mesh points $\left(y_{1, i}, y_{2, j}, t_{n}\right)$, denoted by $(i, j, n)$, for $i=0, \ldots, m_{1}, j=0, \ldots, m_{2}$ and $n=0, \ldots, N$ and set $G_{i, j}^{n} \equiv G(i, j, n)$. With regard to the choice of the finite difference scheme, we opt for the Alternating Direction Implicit (ADI) method described in James and Webber (2000) (which belongs to the general class of operator splitting schemes):

$$
\begin{aligned}
-\frac{G_{i, j}^{n+1}-G_{i, j}^{n+\frac{1}{2}}}{k} & =\frac{1}{2}\left(L_{1, i j}^{n+\frac{1}{2}}+L_{2, i j}^{n+1}\right) \\
-\frac{G_{i, j}^{n+\frac{1}{2}}-G_{i, j}^{n}}{k} & =\frac{1}{2}\left(L_{2, i j}^{n}+L_{1, i j}^{n+\frac{1}{2}}\right),
\end{aligned}
$$


where the operators $L_{1, i j}^{n}$ and $L_{2, i j}^{n}$ are defined by:

$$
\begin{aligned}
& L_{1, i j}^{n}=\frac{\gamma_{1}}{2} \triangle_{y_{1}}^{2} G_{i, j}^{n}+\widetilde{\nu}_{1}(i, j) \triangle_{y_{1}} G_{i, j}^{n}-\frac{\widetilde{\nu}_{3}(i, j)}{2} G_{i, j}^{n} \\
& L_{2, i j}^{n}=\frac{\gamma_{2}}{2} \triangle_{y_{2}}^{2} G_{i, j}^{n}+\widetilde{\nu}_{2}(i, j) \triangle_{y_{2}} G_{i, j}^{n}-\frac{\widetilde{\nu}_{3}(i, j)}{2} G_{i, j}^{n}
\end{aligned}
$$

while $\triangle_{z}^{2} G_{i, j}^{n}$ and $\triangle_{z} G_{i, j}^{n}$, for $z=y_{1}, y_{2}$, are the usual central approximation of the corresponding continuous-version partial derivatives. This ADI scheme suggests the introduction of new function values, $G_{i j}^{n+\frac{1}{2}}$, at the intermediate stage $n+\frac{1}{2}$. The procedure for coming from stage $n+1$ to stage $n$ consists in first finding the intermediate terms $G_{i j}^{n+\frac{1}{2}}$ through equation (A.7a), and second solving equation (A.7b) to obtain the new function value $G_{i j}^{n}$.

Finally, in order to make the finite difference scheme operative, boundary conditions at $i=0, m_{1}$ and $j=0, m_{2}$ must be imposed. Unfortunately, in this particular context neither Neumann nor Dirichlet boundary conditions contribute to giving useful information about the behavior of the solution at the boundary. Thus, the only remaining opportunity is to consider implicit boundary conditions (see James and Webber, 2000, section 12.8). For instance, we use the following approximation for the partial derivatives in the $y_{1}$ direction:

$$
\begin{aligned}
\triangle_{y_{1}} G_{0, j}^{n} & \equiv \frac{-G_{2, j}^{n}+4 G_{1, j}^{n}-3 G_{0, j}^{n}}{2 h_{1}} \\
\triangle_{y_{1}}^{2} G_{0, j}^{n} & \equiv \frac{G_{2, j}^{n}-2 G_{1, j}^{n}+G_{0, j}^{n}}{h_{1}^{2}} \\
\triangle_{y_{1}} G_{m_{1}, j}^{n} & \equiv \frac{G_{m_{1}-2, j}^{n}-4 G_{m_{1}-1, j}^{n}+3 G_{m_{1}, j}^{n}}{2 h_{1}} \\
\triangle_{y_{1}}^{2} G_{m_{1}, j}^{n} & \equiv \frac{G_{m_{1}-2, j}^{n}-2 G_{m_{1}-1, j}^{n}+G_{m_{1}, j}^{n}}{h_{1}^{2}}
\end{aligned}
$$


The same approximation applies for the boundaries in the $y_{2}$ direction. This method produces nearly tri-diagonal linear systems which can be solved efficiently.

\section{References}

M. O. Albizzati and H. Geman. Interest rate risk management and valuation of surrender option in life insurance policies. Journal of Risk and Insurance, 61(4):616-637, 1994.

A. R. Bacinello. Fair valuation of a guaranteed life insurance participating contract embedding a surrender option. Journal of Risk and Insurance, 70 (3):461-487, 2003.

A. R. Bacinello. Endogenous model of surrender conditions in equity-linked life insurance. Insurance: Mathematics \& Economics, 37:270-296, 2005.

M. J. Brennan and E. S. Schwartz. The valuation of american put options. The Journal of Finance, 32(2):449-462, May 1977. Papers and Proceedings of the Thirty-Fifty Annual Meeting of the American Finance Association, Atlantic City, New Jersey, September 16-18, 1976.

M. J. Brennan and E. S. Schwartz. Analyzing convertible bonds. Journal of Financial and Quantitative Analysis, 15(4):907-929, November 1980. Proceedings of the 15th Annual Conference of Western Finance Association, June 19-21, 1980. San Diego (California).

E. Briys and F. de Varenne. On the risk of life insurance liabilities: Debunk- 
ing some common pitfalls. Journal of Risk and Insurance, 64(4):673-694, 1997.

K. C. Chan, G. A. Karolyi, F. A. Longstaff, and A. B. Sandres. An emiprical comparison of alternative models of the short-term interest rates. The Journal of Finance, 47(3):1209-1227, July 1992.

J. C. Cox, J. E Ingersoll, and S. A. Ross. A theory of the term structure of interest rates. Econometrica, 53(2):385-408, March 1985.

A. Grosen and P.L. Jørgensen. Valuation of early exercisable interest rate guarantees. Journal of Risk and Insurance, 64(3):481-503, 1997.

A. Grosen and P.L. Jørgensen. Fair valuation of life insurance liabilities: The impact of interest rate guarantees, surrender options, and bonus policies. Insurance: Mathematics ES Economics, 26:37-57, 2000.

J. James and N. Webber. Interest Rate Modelling. John Wiley \& Sons, 2000.

B. Jensen, P. L. Jørgensen, and A. Grosen. A finite difference approach to the valuation of path dependent life insurance liabilities. The GENEVA Papers on Risk and Insurance - Theory, 26(1):57-84, 2001.

C. Kim. Modeling surrender and lapse rate with economic variables. North American Actuarial Journal, 9(4):56-70, 2005.

W. Kuo, C. Tsai, and W. K. Chen. An empirical study on the lapse rate: The cointegration approach. Journal of Risk and Insurance, 70(3):489-508, 2003. 
R. Stanton. Rational prepayment and the valuation of mortgage backed securities. The Review of Financial Studies, 8(3):677-708, 1995.

M. Steffensen. Intervention options in life insurance. Insurance: Mathematics G Economics, 31:71-85, 2002.

O. A. Vasicek. An equilibrium characterization of the term structure. Journal of Financial Economics, 5:177-188, 1977. 


\section{Working Papers from Finance Research Group}

F-2007-03 Domenico De Giovanni: Lapse Rate Modeling: A Rational Expectation Approach.

F-2007-02 Andrea Consiglio \& Domenico De Giovanni: Pricing the Option to Surrender in Incomplete Markets.

F-2006-09 Peter Løchte Jørgensen: Lognormal Approximation of Complex Pathdependent Pension Scheme Payoffs.

F-2006-08 Peter Løchte Jørgensen: Traffic Light Options.

F-2006-07 David C. Porter, Carsten Tanggaard, Daniel G. Weaver \& Wei Yu: Dispersed Trading and the Prevention of Market Failure: The Case of the Copenhagen Stock Exhange.

F-2006-06 Amber Anand, Carsten Tanggaard \& Daniel G. Weaver: Paying for Market Quality.

F-2006-05 Anne-Sofie Reng Rasmussen: How well do financial and macroeconomic variables predict stock returns: Time-series and cross-sectional evidence.

F-2006-04 Anne-Sofie Reng Rasmussen: Improving the asset pricing ability of the Consumption-Capital Asset Pricing Model.

F-2006-03 Jan Bartholdy, Dennis Olson \& Paula Peare: Conducting event studies on a small stock exchange.

F-2006-02 Jan Bartholdy \& Cesário Mateus: Debt and Taxes: Evidence from bankfinanced unlisted firms.

F-2006-01 Esben P. Høg \& Per H. Frederiksen: The Fractional Ornstein-Uhlenbeck Process: Term Structure Theory and Application.

F-2005-05 Charlotte Christiansen \& Angelo Ranaldo: Realized bond-stock correlation: macroeconomic announcement effects.

F-2005-04 Søren Willemann: GSE funding advantages and mortgagor benefits:

Answers from asset pricing.

F-2005-03 Charlotte Christiansen: Level-ARCH short rate models with regime switching: Bivariate modeling of US and European short rates.

F-2005-02 Charlotte Christiansen, Juanna Schröter Joensen and Jesper Rangvid: Do more economists hold stocks?

F-2005-01 Michael Christensen: Danish mutual fund performance - selectivity, market timing and persistence. 
ISBN 978-87-788-2232-1

Department of Business Studies

Aarhus School of Business

University of Aarhus

Fuglesangs Allé 4

DK-8210 Aarhus V - Denmark

Tel. +4589486688

Fax +4586150188

www.asb.dk 